\title{
Erratum to: Fate and transport of bensulfuron-methyl and imazosulfuron in paddy fields: experiments and model simulation
}

\author{
Kazuhiro Takagi • Ferdinand F. Fajardo • \\ Masumi Ishizaka - Thai Khanh Phong • \\ Hirozumi Watanabe $\cdot$ Julien Boulange
}

Published online: 22 July 2011

(C) Springer-Verlag 2011

Erratum to: Paddy Water Environ

DOI 10.1007/s10333-011-0276-0

Due to an unfortunate turn of events this article has been published with an erroneous version of Figs. 4, 5 and 6. Please find in this erratum the correct Figs. 4, 5 and 6 that should be regarded by the reader as the final version.

The online version of the original article can be found under doi:10.1007/s10333-011-0276-0.

K. Takagi $(\bowtie) \cdot$ M. Ishizaka

National Institute for Agro-Environmental Sciences, Tsukuba,

Ibaraki 305-8604, Japan

e-mail: ktakagi@niaes.affrc.go.jp

F. F. Fajardo

De La Salle University, 2401 Taft Avenue, Malate 1004, Manila,

Philippines

T. K. Phong

Queensland University, 39 Kessels Road, Coopers Plains,

QLD 4108, Australia

H. Watanabe $\cdot$ J. Boulange

Tokyo University of Agriculture and Technology, 3-5-8

Saiwaicho, Fuchu, Tokyo 183-8509, Japan 
Fig. 4 Simulated (continuous line) and observed (open square) bensulfuron-methyl (BSM) concentrations in paddy water (above) and soil paddy field (below)

Fig. 5 Simulated (continuous line) and observed (open square) imazosulfuron (IMS) concentrations in paddy water (above) and soil paddy field (below)

Fig. 6 Pesticide mass balance as \% applied mass for bensulfuron-methyl (above) and imazosulfuron (below)
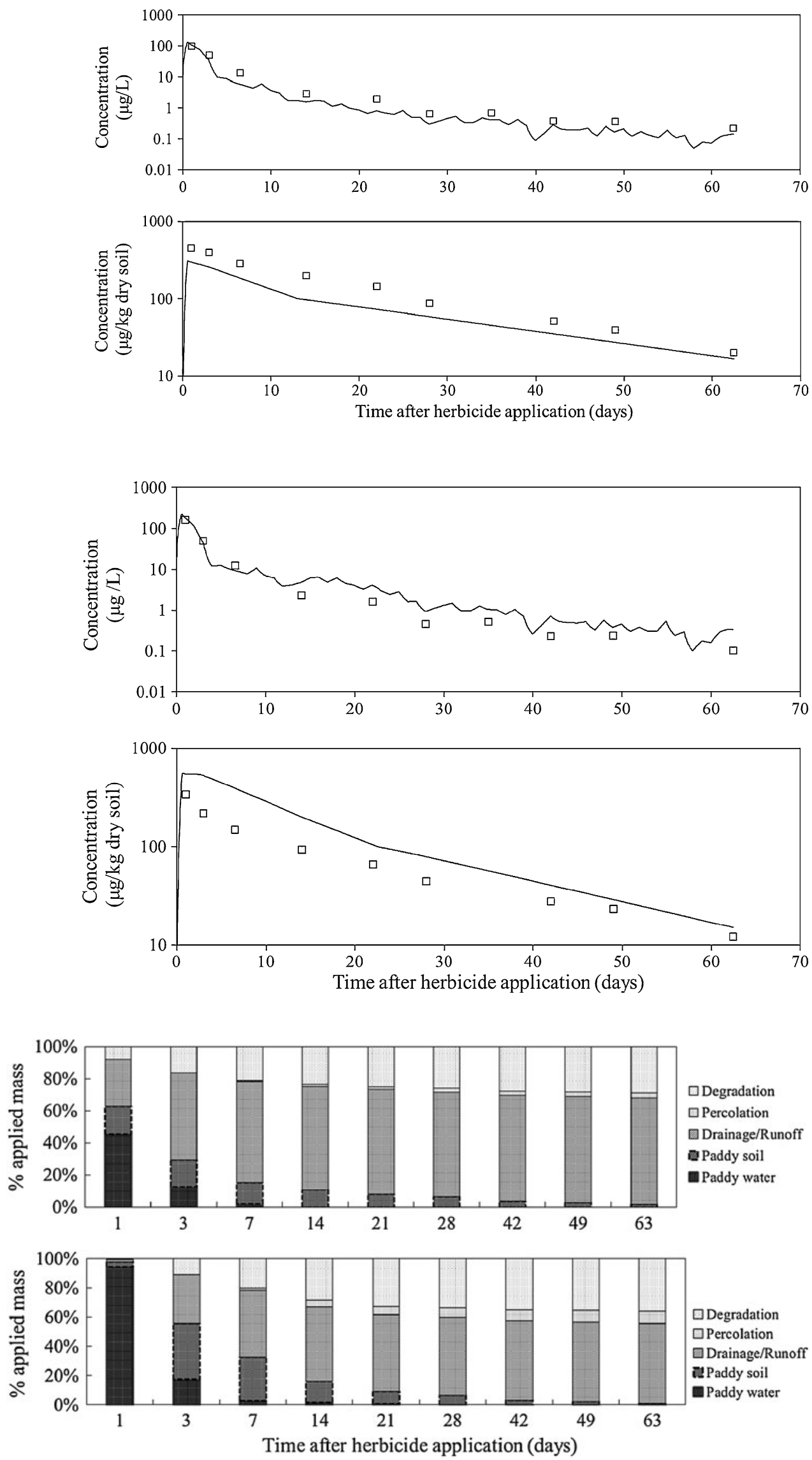